\title{
Treatment with higher dosages of heart failure medication is associated with improved outcome following cardiac resynchronization therapy
}

\author{
Susann Schmidt ${ }^{1}$, David Hürlimann ${ }^{1}$, Christoph T. Starck ${ }^{2}$, Gerhard Hindricks ${ }^{3}$, \\ Thomas F. Lüscher ${ }^{1}$, Frank Ruschitzka ${ }^{1}$, and Jan Steffel ${ }^{1 *}$
}

${ }^{1}$ Department of Cardiology, University Hospital Zurich, University Heart Center, Rämistrasse 100, 8091 Zurich, Switzerland; ${ }^{2}$ Department of Cardiac Surgery,

University Hospital Zurich, Zurich, Switzerland; and ${ }^{3}$ Heart Center, University Hospital Leipzig, Leipzig, Germany

Received 17 January 2013; revised 15 November 2013; accepted 16 November 2013; online publish-ahead-of-print 25 December 2013

This paper was guest edited by Jagmeet P. Singh, Massachusetts General Hospital, Boston, MA, USA (jsingh@partners.org)

Background

Methods

and results

Conclusion

Keywords
Cardiac resynchronization therapy (CRT) is associated with improved morbidity and mortality in patients with chronic heart failure (CHF) on optimal medical therapy. The impact of CHF medication optimization following CRT, however, has never been comprehensively evaluated. In the current study, we therefore investigated the effect of CHF medication dosage on morbidity and mortality in CHF patients after CRT implantation.

Chronic heart failure medication was assessed in 185 patients after CRT implantation. During an overall mean follow-up of 44.6 months, 83 patients experienced a primary endpoint (death, heart transplantation, assist device implantation, or hospitalization for CHF). Treatment with higher dosages of angiotensin-converting enzyme inhibitor (ACE-I) or angiotensin receptor blockers (ARBs) $(P=0.001)$ and beta-blockers $(P<0.001)$ as well as with lower dosages of loop diuretics $(P<0.001)$ was associated with a reduced risk for the primary combined endpoint as well as for all-cause mortality. Echocardiographic super-responders to CRT were treated with higher average dosages of ACE-I/ARBs (68.1 vs. $52.4 \%$, $P<0.01)$ and beta-blockers (59 vs. $42.2 \%, P<0.01)$. During follow-up, the average dosage of loop diuretics was decreased by $20 \%$ in super-responders, but increased by $30 \%$ in non-super-responders $(P<0.03)$.

The use of higher dosages of neurohormonal blockers and lower dosages of diuretics is associated with reduced morbidity and mortality following CRT implantation. Our data imply a beneficial effect of increasing neurohormonal blockade whenever possible following CRT implantation.

Chronic heart failure $\bullet$ Optimal medical therapy $\bullet$ Cardiac resynchronization therapy

\section{Introduction}

Modern treatment of chronic heart failure (CHF) is a multi-modal approach, with optimal medical therapy and device therapy representing the cornerstones of management. Cardiac resynchronization therapy (CRT) is an established treatment for $\mathrm{CHF}$ patients with wide QRS complex and reduced left ventricular (LV) function, based on the reduction in morbidity and mortality observed in large-scale clinical trials. ${ }^{1-5}$ While these studies overall consistently demonstrated a significant improvement for CHF patients, the individual benefit derived from CRT varies largely. ${ }^{6}$ Indeed, a significant number of subjects demonstrate good to excellent response, both clinically and echocardiographically, whereas others experience little or no benefit. The reason for the latter are numerous, with narrow QRS width and the lack of left bundle branch block being most consistently associated with failure to respond. ${ }^{7}$

The other pivotal pillar of modern heart failure therapy is optimal medical management, which can be challenging in these highly fragile patients. Several classes of drugs reduced morbidity and mortality in large-scale clinical trials, including angiotensin-converting enzyme inhibitors (ACE inhibitors), ${ }^{8-10}$ angiotensin receptor blockers (ARBs), ${ }^{11,12}$ beta-blockers, ${ }^{13-15}$ and aldosterone antagonists, ${ }^{16,17}$

*Corresponding author. Tel: +41 44255 4039, Fax: +41 44255 8701, Email: j.steffel@gmx.ch 
which is why they are routinely used in these individuals. Indeed, CRT is only indicated in CHF patients with severely reduced LV function who already are on 'optimal medical therapy' and remain symptomatic. ${ }^{18}$ However, CHF patients do not always tolerate maximal doses of one or all of these important medications. As a result, optimal medical therapy has been defined as the individually tolerated maximum dose of CHF medication, which needs to be established before CRT implantation can be considered. ${ }^{19}$

Once a CRT device has been implanted, however, this situation may change, particularly in patients with a pronounced improvement in LV function on echocardiography. Yet, a large prospective study (IMPROVE-HF) recently demonstrated that doses of evidence-based medication used in CHF patients after CRT implantation were significantly lower than those used in clinical trials. ${ }^{20}$ Another small-scale preliminary study suggested that failure to adapt heart failure medication after CRT is associated with a worse outcome. ${ }^{21}$

Until today, however, the pattern of adaptation of $\mathrm{CHF}$ medication as well as its impact on hard clinical endpoints following CRT implantation has not been comprehensively examined. In the current study, we therefore investigated the association of $\mathrm{CHF}$ medication dosage on morbidity and mortality in a large cohort of CHF patients after CRT implantation.

\section{Methods}

\section{Study population and device implantation}

Our study population consisted of 185 consecutive patients, who underwent CRT implantation at the University Hospital Zurich, Switzerland, between February 2000 and December 2010. Only patients for whom a complete 24-month follow-up with serial clinical assessment was available or who reached a mortality endpoint prior to this time point were included. Indication for CRT implantation was based on the Guidelines of the European Society of Cardiology. ${ }^{18,22}$ This retrospective study was approved by the cantonal and national ethic authorities. Patients were termed as super-responder in case of an improvement in endsystolic volume index $(E S V I) \geq 40 \%$.

Cardiac resynchronization therapy device implantation was mostly performed under local anaesthesia following a standard approach. An LV lead was inserted via a transvenous approach into either a lateral or posterolateral branch of the coronary sinus whenever possible. When transvenous lead placement failed, the LV lead was implanted epicardially. The right atrial and the right ventricular leads were placed conventionally in the right atrial appendage and the right ventricular apex, respectively. Cardiac resynchronization therapy devices and leads from Biotronik, Boston Scientific, Medtronic, and St. Jude Medical were used.

\section{Data acquisition and endpoints}

Data were retrospectively obtained from patient files, general practitioners, external cardiologists, and/or other specialists and also by telephone interview with the patient, if necessary. To comprehensively assess heart failure medication after CRT implantation, we subdivided the 24-month follow-up period into half-monthly intervals. Medication dosages were assessed at every time point and calculated as the percentage of the target dose of each individual drug (see Supplementary material online, Table S1). Dosages administered for $<1$ month were counted as a full month if they were taken longer than 20 days and as half a month, if administered between 10 and 20 days. If a dose was administered for
$<10$ days, it was excluded from the calculation. In the end, a mean dosage was calculated for every drug in every patient over a time period of 24 months after CRT implantation or until a mortality endpoint was reached during this time. This overall mean dosage was subsequently used for statistical analyses. If hospitalization occurred during follow-up, the medication dosage from hospital admission was recorded. Similarly, in case of occurrence of a mortality endpoint (death, heart transplantation, and implantation assist device) before the end of the 2-year followup, medication from hospital admission (if available) or from a preceding medical record was used.

The primary combined endpoint of our study was hospitalization for heart failure or death (defined as death (from any cause), heart transplantation, or assist device implantation). The secondary endpoint of the study was death (from any cause), heart transplantation, or ventricular assist device implantation.

\section{Statistics}

Statistical analyses were performed using SPSS 17.0 (SPSS, Inc., Chicago, IL, USA). The influence of drug dosages on outcome measures was assessed by univariable and multivariable Cox regression analyses, adjusting for QRS duration, bundle branch block, baseline LV ejection fraction (EF), and the respective mediation dosage at baseline. No collinearity was observed between the adjusted variables. The proportional hazard assumption was tested using partial residuals and found to be justified. Cumulative freedom from events for patients with low and high doses of CHF medication were assessed by the Kaplan-Meier method and calculated with the log-rank test. Differences between subgroups were assessed using Student's $t$-test and $\chi^{2}$ test for continuous and categorical variables, respectively. A $P$-value of $<0.05$ was considered significant.

\section{Results}

\section{Study population characteristics}

Baseline characteristics of our patients before CRT implantation are summarized in Table 1 and are reflective of a 'real-world' heart failure cohort. $^{6,23}$ The mean follow-up after CRT implantation was 44.6 months. During follow-up, 83 patients experienced a primary endpoint including 51 deaths, 5 heart transplantations, 8 assist device implantations, and 67 hospitalizations for $\mathrm{CHF}$.

Blood pressure values prior to implantation were low and typical of those found in heart failure populations undergoing CRT implantation. ${ }^{1,4}$ All patients were seen in our specialized heart failure clinic prior to implantation, where great care was taken that the maximum tolerable dose of heart failure medication was installed in every patient prior to implantation. Systolic blood pressure in patients with $<50 \%$ of maximal dose ACE inhibitor/ARB dosage at implantation was lower $(111.2 \pm 8.4$ vs. $117.2 \pm 18 \mathrm{mmHg}, P<$ 0.05), and pro-brain natriuretic peptide (proBNP) levels higher $(4609 \pm 4914.2$ vs. $2251.4 \pm 2580.8 \mathrm{mg} / \mathrm{L}, P<0.001)$, indicating that these were generally sicker patients with more advanced heart failure unable to tolerate higher dosages. Similarly, patients with $<50 \%$ of maximal dose beta-blocker dosage at implantation were older $(64 \pm 11$ vs. $58.4 \pm 10.2$ years, $P<0.005)$ and had higher creatinine $(127.4 \pm 44.9$ vs. $110.8 \pm 43 \mathrm{mmol} / \mathrm{L}, P<0.05)$, as well as proBNP levels $(4276.3 \pm 4644.4$ vs. $1847.1 \pm 1967.7 \mathrm{mg} / \mathrm{L}$, $P<0.005)$ 
Table I Baseline characteristics

\begin{tabular}{|c|c|}
\hline \multicolumn{2}{|l|}{ Clinical } \\
\hline Men & 149/185 (80.5\%) \\
\hline Age at implantation (years) & $63.1 \pm 11$ \\
\hline New implantation & $111 / 185(60 \%)$ \\
\hline PM upgrade & $69 / 185(37.3 \%)$ \\
\hline ICD upgrade & $4 / 185(2.2 \%)$ \\
\hline ICD-CRT implantation & $169 / 185(91.4 \%)$ \\
\hline Systolic BP at implantation $(\mathrm{mmHg})$ & $113.7 \pm 18.4$ \\
\hline Systolic BP at implantation $(\mathrm{mmH})$ & $70.7 \pm 10.5$ \\
\hline Heart rate at implantation (beats/min) & $72.5 \pm 14.1$ \\
\hline NYHA Class I & $8 / 185(4.3 \%)$ \\
\hline NYHA Class II & $39 / 185(21.1 \%)$ \\
\hline NYHA Class III & $129 / 185(69.7 \%)$ \\
\hline NYHA Class IV & $9 / 185(4.9 \%)$ \\
\hline \multicolumn{2}{|l|}{ Risk factors } \\
\hline Diabetes mellitus & $46 / 185(24.9 \%)$ \\
\hline Hypertension & $91 / 185(49.2 \%)$ \\
\hline Positive family history & $62 / 185(33.5 \%)$ \\
\hline Smoker & $42 / 185(22.7 \%)$ \\
\hline Hypercholesterolaemia & $84 / 185(45.4 \%)$ \\
\hline Coronary artery disease & $84 / 185(45.4 \%)$ \\
\hline \multicolumn{2}{|l|}{ Rhythm } \\
\hline Sinus rhythm & $128 / 185(69.2 \%)$ \\
\hline Atrial fibrillation & $24 / 185(13 \%)$ \\
\hline Paced & $33 / 185(17.8 \%)$ \\
\hline QRS (ms) & $158 \pm 34.1$ \\
\hline Left bundle branch block & $109 / 184(59.2 \%)$ \\
\hline \multicolumn{2}{|l|}{ Echocardiography } \\
\hline End-diastolic volume index $\left(\mathrm{mL} / \mathrm{m}^{2}\right)$ & $112.5 \pm 41.9$ \\
\hline End-systolic volume index $\left(\mathrm{mL} / \mathrm{m}^{2}\right)$ & $84.7 \pm 36.1$ \\
\hline Ejection fraction (\%) & $25.7 \pm 7.6$ \\
\hline $\mathrm{RV} / \mathrm{RA}$ pressure gradient $(\mathrm{mmHg})$ & $32.4 \pm 11.1$ \\
\hline
\end{tabular}

PM, pacemaker; ICD, implantable cardioverter-defibrillator; CRT, cardiac resynchronization therapy; BP, Blood pressure; NYHA, New York Heart Association; RV/RA, Right ventricular/right atrial pressure gradient.

\section{Patient outcome related to the dosage of heart failure medication during follow-up}

Patient outcome differed significantly depending on the dose of $\mathrm{CHF}$ drugs used over the follow-up period (Figures 1 and 2, and Table 2). Patients with higher doses of ACE-I/ARBs (Figure $1 \mathrm{~A}, P=0.001$ ) and beta-blockers (Figure $1 B, P<0.001$ ) had a significantly better outcome regarding the combined endpoint of death and hospitalization for CHF. Conversely, the latter occurred less frequently in patients on lower doses of loop diuretics (Figure 1C; $P<0.001$ ). A consistent effect was found regarding the secondary mortality endpoint (death, heart transplantation, or ventricular assist device implantation; Figure 2). Patients on higher doses of ACE-I/ARBs (Figure 2A; $P=0.001$ ) and beta-blockers (Figure $2 B ; P<0.001$ ) and also those with lower doses of loop diuretics (Figure $2 C$ ) during follow-up showed a significantly better survival. A similar picture as for loop diuretics was equally observed for thiazides, both for the combined endpoint and for all-cause mortality. However, the absolute number of patients with thiazide diuretics was low compared with the other (classical) heart failure medication, precluding meaningful Kaplan-Meier analyses.

Hazard ratios for univariable and multivariable analyses are presented in Table 2. On multivariable analysis, the effect of loop diuretic dosage on the combined endpoint was no longer statistically significant - in contrast to its effect on total mortality, which was highly significant even after multivariable adjustment. No significant association was observed between aldosterone antagonist dosage or digitalis dosage and freedom from the combined endpoint or survival ( $P=$ n.s., data not shown).

\section{Heart failure medication during follow-up in CRT super-responders}

Echocardiographic follow-up was available in 152 patients. Mean time from CRT implantation to follow-up echocardiography was 9.4 months. Echocardiographic super-response was defined as an improvement in ESVI $\geq 40 \%$, which was the case in 52 (34.2\%) patients. There was a higher percentage of super-responders among females (48.3 vs. $30.9 \%$ in males, $P=0.08$ ) and among patients with nonischaemic cardiomyopathy (48.8 vs. $16.9 \%, P<00001$ ). Also, both the end-diastolic $\left(99.6 \pm 31\right.$ vs. $\left.117.6 \pm 41.9 \mathrm{~mL} / \mathrm{m}^{2}, P<0.01\right)$ and end-systolic volume index $(72.9 \pm 26.5$ vs. $90 \pm 38.1, P<0.01)$ were lower and EF higher $(27.5 \pm 7.6 \%$ vs. $24.5 \pm 7 \%, P<0.05)$ before CRT implantation in super-responders. At baseline, superresponders were less likely to be on diuretics (65.4 vs. $89 \%, P<$ $0.001)$ and digitalis (7.7 vs. $20.2 \%, P<0.05)$. As expected, superresponders were significantly less likely to reach the combined endpoint (5-year freedom from the combined endpoint 78.1 vs. $43.2 \%$, $P<0.01)$ and the mortality endpoint (86.5 vs. $55.1 \% . P<0.01)$ than those without an improvement in ESVI $<40 \%$ ('non-superresponders').

Medication during the follow-up of super-responders and those patients without an improvement in ESVI $\leq 40 \%$ ('non-superresponders') are presented in Table 3 and Figure 3. The average dose of ACE inhibitor/ARB during follow-up was 68.1 and $52.4 \%$ of the maximal dose in super-responders vs. non-super-responders, respectively $(P<0.01)$; similarly, the average dose of beta-blocker was higher in the former vs. the latter (59 vs. $42.2 \%$ of maximum dose, $P<0.01)$. In contrast, no statistically significant difference with respect to average dose diuretics or digitalis was seen between the two groups, although numerical differences were pointing in the same direction. Super-responders were more likely to be on $>50 \%$ of ACE inhibitor dose than non-super-responders $(63.5$ vs. $45 \%, P<0.05)$. Conversely, the former were less likely to be on $>10 \%$ maximal dose of loop diuretics (17.3 vs. $45 \%, P<0.001)$ or thiazides (3.8 vs. $15 \%, P<0.05$ ). A different cut-off $(>10 \%)$ was used for diuretics owing to the fact that very few patients were on high absolute doses of diuretics.

During follow-up, the dosage of loop diuretics was on average decreased by $20 \%$ in super-responders, whereas it was increased by $30 \%$ on average in non-super-responders $(P<0.03$, Table 4$)$. Similarly, the percentage of patients experiencing an increase in loop 

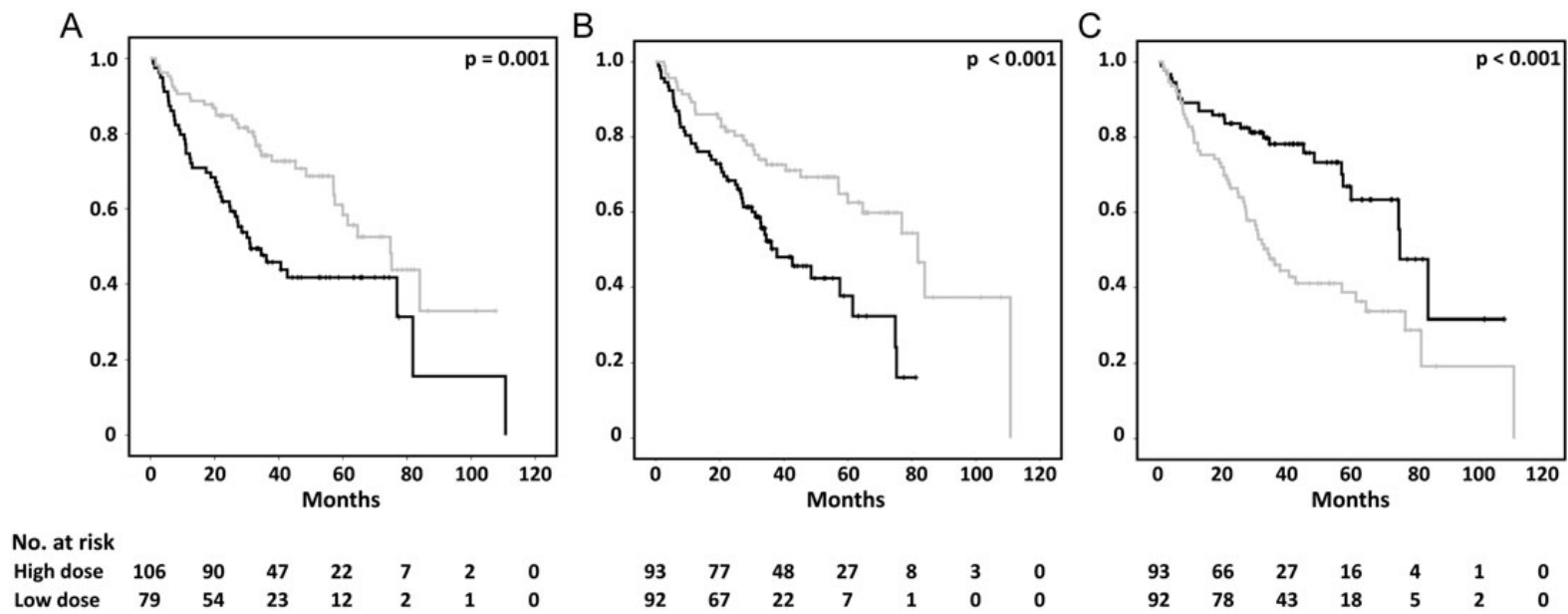

$$
\begin{array}{lllllll}
93 & 77 & 48 & 27 & 8 & 3 & 0 \\
92 & 67 & 22 & 7 & 1 & 0 & 0
\end{array}
$$

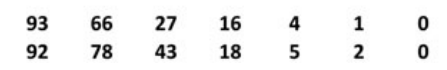

Figure I Freedom from the combined endpoint for patients with high ( $\geq$ median, grey) dosage and low ( $<$ median, black) dosage of angiotensinconverting enzyme inhibitor/angiotensin receptor blocker $(A)$, beta-blockers $(B)$, and loop diuretics $(C)$ during the first 24 months after cardiac resynchronization therapy (CRT) implantation.
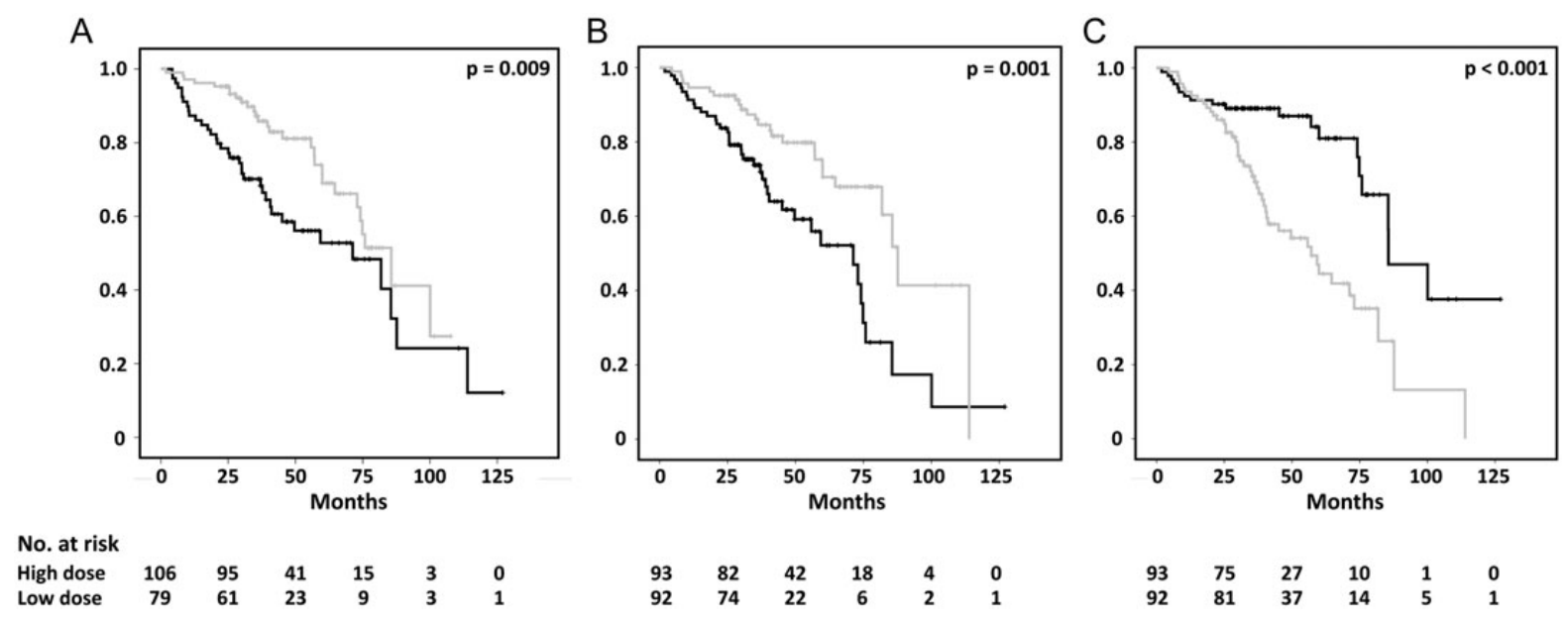

Figure 2 Freedom from death for patients with high ( $\geq$ median, grey) dosage and low ( $<$ median, black) dosage of angiotensin-converting enzyme inhibitor/angiotensin receptor blocker $(A)$, beta-blockers $(B)$, and loop diuretics $(C)$ during the first 24 months after CRT implantation.

diuretics (17.3 vs. $49 \%, P<0.001)$ or thiazides ( 0 vs. $12 \%, P<0.01)$ was lower in super-responders vs. non-super-responders.

\section{Discussion}

In the current study, we found that the use of higher dosages of neurohormonal blockers and lower dosages of diuretics is associated with reduced morbidity and mortality after CRT implantation. Furthermore, we demonstrate that super-responders to CRT were treated with higher doses of ACE inhibitor/ARB and beta-blockers, but with lower doses of loop diuretics following CRT implantation. To the best of our knowledge, this is the first study to comprehensively assess the effect of different doses of contemporary heart failure medication on clinical outcomes in CRT patients. Our findings raise several important issues regarding the medical management of these patients.

\section{Effect of renin-angiotensin-aldosterone system blockade}

Over the last 25 years, numerous pivotal trials have established the role of neurohormonal blockade in CHF patients to improve morbidity and mortality. Indeed, ACE inhibitors were demonstrated to lead to improve the clinical outcome in several landmark trials including CONSENSUS, SOLVD, and SAVE. ${ }^{8-10}$ Later, ARBs were found to be similarly effective, especially in patients intolerant to ACE inhibitors. ${ }^{11,12}$ Further studies have suggested an increasing benefit with higher dosages of neurohormonal blockade. In the Assessment of Treatment with Lisinopril And Survival (ATLAS) trial, patients on 
Table 2 Hazard ratios of different heart failure medication dosages during follow-up after CRT implantation

\begin{tabular}{|c|c|c|c|c|c|c|}
\hline & \multicolumn{3}{|c|}{ Univariable } & \multicolumn{3}{|c|}{ Multivariable } \\
\hline & HR & $95 \% \mathrm{Cl}$ & $P$-value & HR & $95 \% \mathrm{Cl}$ & $P$-value \\
\hline \multicolumn{7}{|l|}{ Combined endpoint } \\
\hline $\begin{array}{l}\text { Angiotensin-converting enzyme I } \\
\text { inhibitor/angiotensin receptor blocker }\end{array}$ & 0.985 & $0.978-0.992$ & $<0.001$ & 0.980 & $0.970-0.990$ & $<0.001$ \\
\hline Beta-blocker & 0.984 & $0.976-0.991$ & $<0.001$ & 0.984 & $0.974-0.994$ & 0.002 \\
\hline Loop diuretics & 1.035 & $1.024-1.046$ & $<0.001$ & 1.007 & $0.986-1.029$ & 0.524 \\
\hline \multicolumn{7}{|l|}{ Mortality } \\
\hline $\begin{array}{l}\text { Angiotensin-converting enzyme I } \\
\text { inhibitor/angiotensin receptor blocker }\end{array}$ & 0.986 & $0.977-0.994$ & 0.001 & 0.980 & $0.969-0.992$ & 0.001 \\
\hline Beta-blocker & 0.984 & $0.976-0.992$ & $<0.001$ & 0.982 & $0.971-0.994$ & 0.003 \\
\hline Loop diuretics & 1.038 & $1.025-1.050$ & $<0.001$ & 1.023 & $1.005-1.041$ & 0.014 \\
\hline
\end{tabular}

Multivariable analysis adjusted for QRS duration, bundle branch block, baseline left ventricular (LV) ejection fraction (EF), improvement of LVEF, and the respective medication at baseline. Hazard ratios (HRs) were calculated for every $1 \%$ change in average CHF medication over the follow-up period. As such, an HR of 0.985 (univariable analysis for angiotensin-converting enzyme I inhibitor/angiotensin receptor blocker) indicates an increase in the hazard by $1.52 \%$ with every $1 \%$ decrease in average dosage of angiotensin-converting enzyme I inhibitor/angiotensin receptor blocker during follow-up.

Table 3 Medication of super-responders and non-super-responders during follow-up

\begin{tabular}{|c|c|c|c|c|}
\hline & Total & $\begin{array}{l}\text { Super-responder } \\
52 / 152(34 \%)\end{array}$ & $\begin{array}{l}\text { Non-super-responder } \\
100 / 152(66 \%)\end{array}$ & $P$-value \\
\hline \multicolumn{5}{|c|}{ Average dose (\% of maximal dose) } \\
\hline ACE-I/ARB & $57.7 \pm 34.5$ & $68.1 \pm 33.9$ & $52.4 \pm 33.7$ & $<0.01$ \\
\hline Beta-blockers & $48 \pm 37.2$ & $59 \pm 42.8$ & $42.2 \pm 32.7$ & $<0.01$ \\
\hline Spironolactone & $20.5 \pm 22.6$ & $20.5 \pm 19.7$ & $20.5 \pm 24.1$ & 0.94 \\
\hline Loop diuretics & $12 \pm 14.9$ & $9.6 \pm 14.8$ & $13.3 \pm 14.9$ & 0.16 \\
\hline Thiazides & $3.2 \pm 6.1$ & $2.1 \pm 4.3$ & $3.7 \pm 6.8$ & 0.13 \\
\hline \multirow[t]{2}{*}{ Digitalis } & $8.8 \pm 21$ & $6.2 \pm 21.1$ & $10.2 \pm 21$ & 0.29 \\
\hline & & $\%$ of Super-responder & $\%$ of Non-super-responder & \\
\hline \multicolumn{5}{|c|}{$\%$ of Patients with $>50 \%(*>10 \%)$ dose } \\
\hline ACE-I/ARB & $70 / 152(46.1 \%)$ & $31 / 52(59.6 \%)$ & $39 / 100(39 \%)$ & $<0.02$ \\
\hline Beta-blockers & $48 / 152(31.6 \%)$ & $21 / 52(40.4 \%)$ & $27 / 100(27 \%)$ & 0.09 \\
\hline Spironolactone* & $93 / 152(61.2 \%)$ & $35 / 52(67.3 \%)$ & $58 / 100(58 \%)$ & 0.26 \\
\hline Loop diuretics* & $54 / 152(35.5 \%)$ & $9 / 52(17.3 \%)$ & $45 / 100(45 \%)$ & $<0.001$ \\
\hline Thiazides* & $17 / 152(11.2 \%)$ & $2 / 52(3.8 \%)$ & 15/100 (15\%) & $<0.05$ \\
\hline Digitalis* & $1 / 152(0.7 \%)$ & $0 / 52(0 \%)$ & $1 / 100(1 \%)$ & 0.47 \\
\hline
\end{tabular}

ACE-I inhibitor, angiotensin-converting enzyme I inhibitor; ARB, angiotensin receptor blocker.

$* \%$ of Patients with $>50 \%(*>10 \%)$ dose.

high-dose lisinopril had a $15 \%$ reduced risk of death or CHF hospitalization. ${ }^{24}$ Similar findings have been obtained in the Heart failure Endpoint evaluation of Angiotensin II Antagonist Losartan (HEAAL) trial for ARBs. ${ }^{25}$ It has therefore been recommended to adjust medication dosage to the maximum tolerated dose. ${ }^{19}$ Of the reasons why ACE-I/ ARBs are not uptitrated, symptomatic hypotension and renal insufficiency are most frequent. Also in our cohort, patients with $<50 \%$ of maximal dose ACE inhibitor/ARB dosage during follow-up had significantly higher baseline creatinine (142.6 \pm 59.3 vs. $110.7 \pm$ $34.3 \mathrm{mmol} / \mathrm{L}, P<0.0001)$ and proBNP levels $(4598 \pm 4251.6 \mathrm{vs}$. $3039.8 \pm 4089.6 \mathrm{mg} / \mathrm{L}, P<0.03)$, indicating more advanced renal disease in these patients. In addition, subjective symptoms including dizziness and (pre-) syncope likely contributed to the lack of further uptitration.

After CRT implantation, a pilot study in 91 patients reported an improvement in morbidity and mortality with increasing dosages 

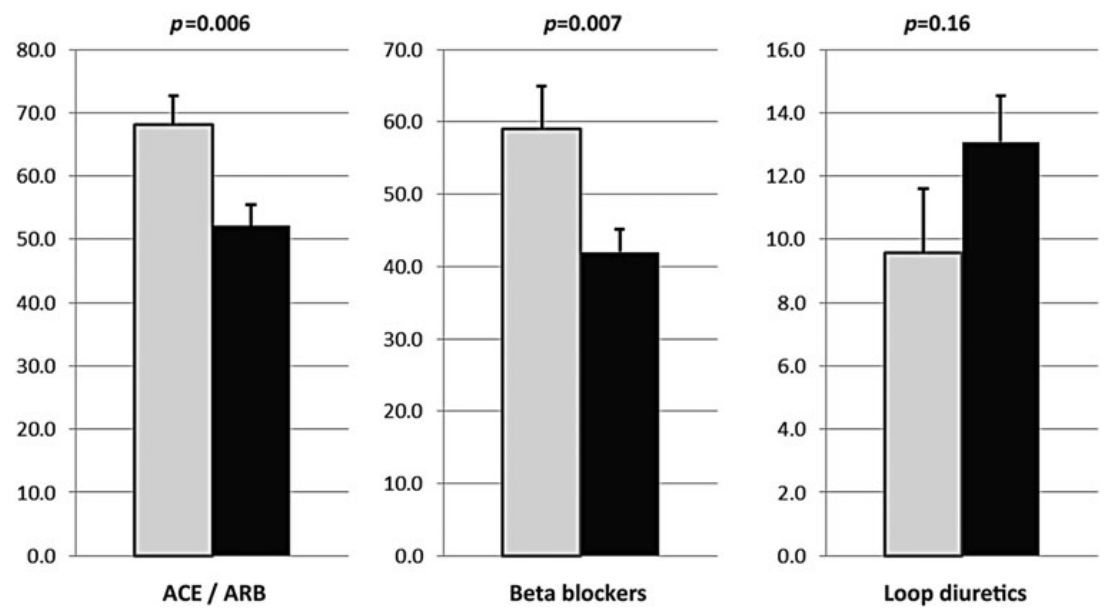

Figure 3 Doses of heart failure medication of super-responders (grey) vs. non-super-responders (black). Data are presented as average dose during follow-up ( \pm standard error of the mean). Super-response was defined as a decrease in ESVI $\geq 40 \%$.

Table 4 Medication change in super-responders and non-super-responders over the follow-up

\begin{tabular}{|c|c|c|c|c|}
\hline & Total & $\begin{array}{l}\text { Super-responder } \\
52 / 152(34 \%)\end{array}$ & $\begin{array}{l}\text { Non-super-responder } \\
100 / 152(66 \%)\end{array}$ & $P$-value \\
\hline \multicolumn{5}{|c|}{ Average fold-increase over 2 years } \\
\hline ACE-I/ARB & $1.4 \pm 1.6$ & $1.4 \pm 1.7$ & $1.3 \pm 1.5$ & 0.82 \\
\hline Beta-blockers & $1.3 \pm 1.1$ & $1.5 \pm 1.3$ & $1.2 \pm 1.1$ & 0.28 \\
\hline Spironolactone & $1 \pm 1.4$ & $0.9 \pm 1$ & $1.1 \pm 1.6$ & 0.50 \\
\hline Loop diuretics & $1.1 \pm 1.5$ & $0.8 \pm 0.8$ & $1.3 \pm 1.7$ & $<0.03$ \\
\hline Thiazides & $0.3 \pm 0.6$ & $0.2 \pm 0.4$ & $0.4 \pm 0.7$ & 0.19 \\
\hline \multirow[t]{2}{*}{ Digitalis } & $0.3 \pm 1.4$ & $0.3 \pm 1.1$ & $0.4 \pm 1.5$ & 0.71 \\
\hline & & $\%$ of Super-responder & $\%$ of Non-super-responder & \\
\hline \multicolumn{5}{|c|}{$\%$ of Patients with dose increase } \\
\hline ACE-I/ARB & $47 / 152(30.9 \%)$ & $15 / 52(28.8 \%)$ & $32 / 100(32 \%)$ & 0.69 \\
\hline Beta-blockers & $64 / 152(42.1 \%)$ & $26 / 52(50 \%)$ & $38 / 100(38 \%)$ & 0.16 \\
\hline Spironolactone & $30 / 152(19.7 \%)$ & $8 / 52(15.4 \%)$ & $22 / 100(22 \%)$ & 0.33 \\
\hline Loop diuretics & $57 / 152(37.5 \%)$ & $9 / 52(17.3 \%)$ & $48 / 100(48 \%)$ & $<0.001$ \\
\hline Thiazides & $12 / 152(7.9 \%)$ & $0 / 52(0 \%)$ & $12 / 100(12 \%)$ & $<0.01$ \\
\hline Digitalis & $8 / 152$ (5.3\%) & $4 / 52(7.7 \%)$ & $4 / 100(4 \%)$ & 0.33 \\
\hline
\end{tabular}

ACE-I inhibitor, angiotensin-converting enzyme I inhibitor; ARB, angiotensin receptor blocker.

of ACE inhibitors or ARBs. ${ }^{26}$ This smaller scale preliminary study, however, only investigated the effect of medication dose at 6 months after CRT implantation and its relationship on subsequent outcomes, whereas in the current study we integrated drug dosage over the whole 24 months after implantation. Indeed, the latter is of critical importance in order to account for the frequent adaptations in CHF medication, which need to be performed in often relatively unstable patients. Our findings are furthermore consistent with a recent study, in which clinical responders to CRT were more likely to be on the target dose of ACE inhibitors and beta-blockers when compared with non-responders. ${ }^{27}$ This study, however, only investigated the effect on clinical response (improvement in New York Heart Association class by $\geq 1$ ), and furthermore only assessed accomplishment of target dose in a binary manner; in contrast, we minutely investigated the effect of drug dosage during follow-up and its effect both on echocardiographic super-response and on clinical outcome. The data from our study hence extend these preliminary findings, demonstrating a statistically significant, dose-dependent decrease in morbidity and mortality for increasing dosages of ACE inhibitors (or ARB) with our comprehensive mode of assessment. 
Aldosterone antagonists are equally established in the treatment of CHF patients, based on the landmark RALES, EMPHASIS-HF, and EPHESUS studies. ${ }^{16,17}$ There are no strong data supporting the use of higher vs. lower doses of aldosterone antagonists in heart failure aside from the general recommendation to employ the dosages used in the aforementioned landmark trials. Interestingly, in our cohort, no dose-dependent association with clinical outcome was observed with aldosterone antagonists. Furthermore, the dosage of aldosterone antagonists was not higher in superresponders when compared with non-super-responders. These findings may be due to the inherent difficulty (and fear) of increasing aldosterone antagonist dosages due to the risk of hyperkalaemia and worsening renal function, ${ }^{28}$ especially on the basis of already established and, ideally, maximized ACE inhibitor/ARB therapy.

\section{Effect of beta-blocker therapy}

In the three pivotal clinical trials investigating the use of beta-blockers in CHF-Cardiac Insufficiency Bisoprolol Study II (CIBIS II), Carvedilol Prospective Randomized Cumulative Survival (COPERNICUS), and Metoprolol CR/XL Randomized Intervention Trial in Congestive Heart Failure (MERIT-HF) —an approximate 34\% relative reduction in mortality was observed in each of the studies. ${ }^{13-15}$ Similar to ACE-inhibitors, treatment with the maximum tolerated dosage is recommended also for beta-blockers in CHF patients. ${ }^{19}$ Patients with $<50 \%$ of maximal beta-blocker dosage during follow-up in our cohort were older $(64.8 \pm 11.3$ vs. $60 \pm 10$ years, $P<0.005)$ and had higher baseline creatinine $(131.1 \pm 54.4$ vs. $112.3 \pm$ $35.2 \mathrm{mmol} / \mathrm{L}, P<0.02)$ and proBNP levels $(4512.5 \pm 4547.6$ vs. $2294.6 \pm 3155.6 \mathrm{mg} / \mathrm{L}, P<0.002$ ), indicating that they were generally sicker and unable to tolerate higher dosages. In addition, similar to ACE-I/ARBs, subjective symptoms including dizziness and (pre-) syncope likely prohibited further uptitration.

In patients after CRT implantation, the complete lack of betablocker therapy has been shown to be associated with increased mortality. ${ }^{29}$ Similarly, in the small CARIBE-HF trial, 15 patients receiving a CRT were able to tolerate higher dosages of beta-blockers compared with 69 patients without CRT. ${ }^{30}$ The effect of beta-blocker dosing on outcomes after CRT, however, has so far not been adequately assessed. The impressive dose-dependent reduction in mortality associated with increasing beta-blocker dosage observed in our study, hence, represents an important piece of guidance for medical therapy after CRT implantation. The fact that this effect was highly significant and independent of potential clinical and echocardiographic confounders appears to support the importance of attempting to obtain an adequate beta-blocker dosage in these patients.

\section{Effect of digitalis}

There is some ambiguity regarding the effect of digoxin on cardiovascular endpoints, which has been extensively discussed on the basis of recently published trials and observations and which has not been finally solved. Most of the evidence supporting the use of digitalis in CHF patients stems from the DIG trial, in which an effect on morbidity (CHF hospitalization) but not mortality could be demonstrated. ${ }^{31}$ Several subgroup analyses from other large trials, most prominently the AFFIRM trial, have equally investigated the effect of digoxin with partly conflicting results. ${ }^{32,33}$ The most frequent reason for prescription of digitalis is advanced heart failure and heart failure with atrial fibrillation (AF). Indeed, in our cohort, patients on digitalis had higher proBNP levels at baseline $(5332.9 \pm 5378.4$ vs. $3332.2 \pm$ $3851 \mathrm{mg} / \mathrm{L}, P<0.03$ ) with similar creatinine levels, indicating a more advanced degree of heart failure; furthermore, digitalis was more frequently used in patients with AF when compared with those without AF [10 of $24(41.7 \%)$ vs. 22 of $161(13.7 \%), P<0.001]$.

In our study, we observed no association between the digoxin dose and outcome. However, more non-super-responders were still on digitalis during follow-up after CRT, probably reflecting the reduced clinical state of these patients compared with superresponders. Indeed, unlike RAAS inhibitors and beta-blockers, an increasing dosage of digitalis is generally not associated with the improved outcome and may, in fact, cause harm up to digitalis toxicity. Also in the long term, an increase in hospitalizations for potential digoxin toxicity and arrhythmic mortality and also for higher all-cause mortality have been reported with higher doses of digoxin. ${ }^{31,34}$

\section{Effect of diuretics}

The effect of diuretics on morbidity and mortality has not been studied in the same manner as for ACE inhibitors, beta-blockers, or aldosterone antagonists. It is known that volume overload and congestion is the leading cause of hospitalization in acute decompensated heart failure, which is why the primary use of diuretics lies in the symptomatic treatment to reach and maintain the patient's 'dry weight'. ${ }^{18}$ Consequently, in our study, CRT super-responders were less likely to be treated with diuretics, and if so required smaller doses. This is consistent with previous studies, including a subgroup analysis from the DIG trial, where an increased long-term risk for mortality and hospitalizations was observed with chronic diuretic use in CHF patients. ${ }^{35}$

Interestingly, a higher dosage of loop diuretics was associated with a higher hazard for the combined endpoint on univariable, but not multivariable, analysis. These findings indicate that other parameters - likely baseline EF and loop diuretic dosage prior to CRT implantation - play an important role regarding subsequent CHF hospitalization. Nevertheless, higher dosages of loop diuretics were associated with a worse outcome regarding total mortality even after adjusting for these factors. Our overall data are consistent with several other observational studies, which illustrated a worse outcome in patients with advanced heart failure on higher doses of diuretics. ${ }^{36,37}$ The present study's results hence extend these previous observations to CHF patients after CRT implantation. Just like our data, however, these studies are unable to answer the question whether adverse outcomes in patients on higher doses of diuretics are reflective of the impaired clinical condition in these patients or whether, conversely, diuretic use in higher doses may in itself have a negative impact on mortality. This aspect will hence require further study to clarify.

\section{Improved outcome with optimized chronic heart failure medication after cardiac resynchronization therapy-a causality conundrum}

Our data indicate that an improvement in medical therapy (increase in neurohormonal blockade and decrease in diuretics use) is 
associated with improved morbidity and mortality after CRT. Our results further demonstrate that super-responders to CRT are treated with higher doses of both ACE inhibitors/ARBs and betablockers, whereas loop diuretics are more likely to be decreased in super-responders and increased in non-super-responders. One of the obvious questions about our findings is whether increased neurohormonal blockade is a result of response to CRT (and the resulting possibility to increase the dose of these medications) or, conversely, LV reverse remodelling and improved clinical outcome are a result of the increase in neurohormonal blockade. By virtue of its retrospective nature, our study cannot answer this question on a causal basis. However, some aspects of our data imply a combination of the two to be operative.

A very small preliminary study in 30 patients previously demonstrated the lack of optimal medical therapy at baseline to be associated with less pronounced reverse remodelling after CRT. ${ }^{38}$ In our study, however, great care was taken that patients only undergo CRT implantation if they are truly on optimal medical therapy prior to implantation, i.e. on the maximum tolerated dose of heart failure medication. Furthermore, the effect of drug dosage during follow-up appeared independently associated with the clinical outcome even if adjusted for the respective baseline dosage. An increase during follow-up is hence likely the result of response to CRT, and not the other way around.

By restoring both mechanical and, probably more importantly, electrical synchronicity, CRT leads to an improvement in heart failure symptoms and blood pressure. ${ }^{39}$ As a result of this, patients responding to CRT may tolerate an increase in neurohormonal blockade during follow-up, which had been prevented due to the aforementioned reasons prior to CRT. Increased beta-blocker dosage and also ACE inhibitor/ARB dosage appeared independently associated with an improved outcome in our study, even if adjusted for clinical and echocardiographic parameters at baseline. The direct effect of ACE inhibitor/ARB therapy on ventricular reverse remodelling (e.g. increase in LVEF) does not appear to be as pronounced as that observed with beta-blockers. ${ }^{18,40-42}$ Taken together, these findings hence strongly imply mechanisms other than an improvement in echocardiographic parameters to be involved in the beneficial effect of increased beta-blocker and ACE-I/ARB dosage after CRT.

\section{Limitations}

Some differences in baseline parameters are pertinent to our study cohort which deserves to be commented on. Echocardiographic LV dysfunction at baseline was worse in non-super-responders when compared with super-responders. These findings imply that less sick patients may have had a higher chance of becoming superresponders to CRT than those who are already past the "point of no return'. A similar observation has recently been made in a large registry ${ }^{43}$ and also in a sub-analysis of MADIT-CRT. ${ }^{44}$ Due to the (absolute) low number of outcome events, correction for only a selected number of variables was feasible for a valid multivariable analysis. Great care and efforts were taken to minutely assess medication status of our patients, enabling calculation of the presented results including the association between clinical outcome and echocardiographic super-response. In contrast, analysis of medication change as a time-dependent co-variable was beyond the scope of our current study. This retrospective study is finally limited by the fact that it was restricted to patients with continuous clinical and mid-term echocardiographic follow-up at our institution, potentially inducing a selection bias by including only patients from a tertiary referral centre. However, these aspects are inherent to any 'real-world' retrospective analyses from such centres. On the flipside, our data are representative of broad current day CRT use and should hence be of a great value for heart failure specialists involved in the care of these patients. Indeed, in the absence of a randomized clinical trial on this topic (which is unlikely to be performed), the current data represent considerable evidence supporting the use of higher dosages of neurohormonal blockade in CRT patients.

\section{Conclusions}

The use of higher doses of neurohormonal blockade and lower doses of diuretics is associated with reduced morbidity and mortality following CRT implantation. Although our data are, by virtue of their derivation from a retrospective cohort, only hypothesis generating, they strongly imply a beneficial effect of increasing neurohormonal blockade whenever possible following CRT implantation. Our results hence support this general recommendation from the 2012 ESC heart failure guidelines and extend it to patients after CRT implantation.

\section{Supplementary material}

Supplementary material is available at European Heart Journal online.

Conflict of interest: S.S.: none; D.H.: educational grants from Boston Scientific and Medtronic, speaker honoraria, and consulting fees from Biotronik, Sorin, St. Jude Medical, and Medtronic. C.T.S.: none; G.H.: research support and speakers' honoraria from Biotronik and St. Jude Medical; T.F.L.: research grants from Biotronik, Medtronic, and St. Jude; F.R.: research grants and consulting fees from Biotronik, speaker honoraria from Biotronik, and Boston Scientific. J.S.: research support from St. Jude Medical, Biotronik, and Medtronic; consulting honoraria from Biotronik, Sorin, St. Jude Medical, and Medtronic.

\section{Funding}

Research reported in this manuscript was supported by Biotronik (Baar/ Switzerland), Medtronic (Tolechenaz/Switzerland), and St. Jude Medical (Zurich/Switzerland).

\section{References}

1. Cleland JG, Daubert JC, Erdmann E, Freemantle N, Gras D, Kappenberger L, Tavazzi $L$. The effect of cardiac resynchronization on morbidity and mortality in heart failure. N Engl J Med 2005;352:1539-1549.

2. Abraham WT, Fisher WG, Smith AL, Delurgio DB, Leon AR, Loh E, Kocovic DZ, Packer M, Clavell AL, Hayes DL, Ellestad M, Trupp RJ, Underwood J, Pickering F, Truex C, McAtee P, Messenger J. Cardiac resynchronization in chronic heart failure. N Engl J Med 2002;346:1845-1853.

3. Bristow MR, Saxon LA, Boehmer J, Krueger S, Kass DA, De Marco T, Carson P, DiCarlo L, DeMets D, White BG, DeVries DW, Feldman AM. Cardiacresynchronization therapy with or without an implantable defibrillator in advanced chronic heart failure. N Engl J Med 2004;350:2140-2150.

4. Moss AJ, Hall WJ, Cannom DS, Klein H, Brown MW, Daubert JP, Estes NA III, Foster E, Greenberg H, Higgins SL, Pfeffer MA, Solomon SD, Wilber D, Zareba W. Cardiac-resynchronization therapy for the prevention of heart-failure events. N Engl I Med 2009;361:1329-1338. 
5. Raftopoulou M, Hall A. Cell migration: Rho gtpases lead the way. Dev Biol 2004;265 23-32.

6. Steffel J, Milosevic G, Hurlimann A, Krasniqi N, Namdar M, Ruschitzka F, Luscher TF, Duru F, Holzmeister J, Hurlimann D. Characteristics and long-term outcome of echocardiographic super-responders to cardiac resynchronisation therapy: 'Real world' experience from a single tertiary care centre. Heart 2011;97:1668-1674.

7. Zareba W, Klein H, Cygankiewicz I, Hall WJ, McNitt S, Brown M, Cannom D, Daubert JP, Eldar M, Gold MR, Goldberger JJ, Goldenberg I, Lichstein E, Pitschner H, Rashtian M, Solomon S, Viskin S, Wang P, Moss AJ, Investigators M-C. Effectiveness of cardiac resynchronization therapy by QRS morphology in the multicenter automatic defibrillator implantation trial-cardiac resynchronization therapy (MADIT-CRT). Circulation 2011;123:1061-1072.

8. Effect of enalapril on survival in patients with reduced left ventricular ejection fractions and congestive heart failure. The SOLVD investigators. N Engl J Med 1991;325: 293-302.

9. Pfeffer MA, Braunwald E, Moye LA, Basta L, Brown EJ Jr, Cuddy TE, Davis BR, Geltman EM, Goldman S, Flaker GC et al. Effect of captopril on mortality and morbidity in patients with left ventricular dysfunction after myocardial infarction. Results of the survival and ventricular enlargement trial. The SAVE investigators. NEnglJMed 1992;327:669-677.

10. Effects of enalapril on mortality in severe congestive heart failure. Results of the cooperative north scandinavian enalapril survival study (consensus). The CONSENSUS Trial Study Group. N Engl J Med 1987;316:1429-1435.

11. Cohn JN, Tognoni G, Valsartan Heart Failure Trial I. A randomized trial of the angiotensin-receptor blocker valsartan in chronic heart failure. N Engl J Med 2001; 345:1667-1675.

12. Granger CB, McMurray J], Yusuf S, Held P, Michelson EL, Olofsson B, Ostergren J, Pfeffer MA, Swedberg K, Investigators C. Committees. Effects of candesartan in patients with chronic heart failure and reduced left-ventricular systolic function intolerant to angiotensin-converting-enzyme inhibitors: the charm-alternative trial. Lancet 2003;362:772-776.

13. The cardiac insufficiency bisoprolol study ii (CIBIS-II): a randomised trial. Lancet 1999;353:9-13.

14. Effect of metoprolol $C R / X L$ in chronic heart failure: metoprolol $C R / X L$ randomised intervention trial in congestive heart failure (MERIT-HF). Lancet 1999;353: 2001-2007.

15. Packer M, Coats AJ, Fowler MB, Katus HA, Krum H, Mohacsi P, Rouleau JL, Tendera M, Castaigne A, Roecker EB, Schultz MK, DeMets DL, Carvedilol Prospective Randomized Cumulative Survival Study G. Effect of carvedilol on survival in severe chronic heart failure. N Engl ] Med 2001;344:1651-1658.

16. Pitt B, Zannad F, Remme WJ, Cody R, Castaigne A, Perez A, Palensky J, Wittes J. The effect of spironolactone on morbidity and mortality in patients with severe heart failure. Randomized aldactone evaluation study investigators. N Engl J Med 1999; 341:709-717.

17. Zannad F, McMurray JJ, Krum H, van Veldhuisen DJ, Swedberg K, Shi H, Vincent J, Pocock SJ, Pitt B; Group E-HS. Eplerenone in patients with systolic heart failure and mild symptoms. N Engl J Med 2011;364:11-21.

18. McMurray J], Adamopoulos S, Anker SD, Auricchio A, Bohm M, Dickstein K, Falk V, Filippatos G, Fonseca C, Gomez-Sanchez MA, Jaarsma T, Kober L, Lip GY, Maggioni AP, Parkhomenko A, Pieske BM, Popescu BA, Ronnevik PK, Rutten FH, Schwitter J, Seferovic P, Stepinska J, Trindade PT, Voors AA, Zannad F, Zeiher A, Task Force for the D, Treatment of A, Chronic Heart Failure of the European Society of C, Bax J, Baumgartner H, Ceconi C, Dean V, Deaton C, Fagard R, Funck-Brentano C, Hasdai D, Hoes A, Kirchhof P, Knuuti J, Kolh P, McDonagh T, Moulin C, Popescu BA, Reiner Z, Sechtem U, Sirnes PA, Tendera M, Torbicki A, Vahanian A, Windecker S, McDonagh T, Sechtem U, Bonet LA, Avraamides P, Ben Lamin HA, Brignole M, Coca A, Cowburn P, Dargie H, Elliott P, Flachskampf FA, Guida GF, Hardman S, lung B, Merkely B, Mueller C, Nanas JN, Nielsen OW, Orn S, Parissis JT, Ponikowski P; Guidelines ESCCfP. ESC guidelines for the diagnosis and treatment of acute and chronic heart failure 2012: the task force for the diagnosis and treatment of acute and chronic heart failure 2012 of the European Society of Cardiology. Developed in collaboration with the heart failure association (HFA) of the ESC. Eur J Heart Fail 2012;14:803-869.

19. McMurray J, Cohen-Solal A, Dietz R, Eichhorn E, Erhardt L, Hobbs FD, Krum H, Maggioni A, McKelvie RS, Pina IL, Soler-Soler J, Swedberg K. Practical recommendations for the use of ACE inhibitors, beta-blockers, aldosterone antagonists and angiotensin receptor blockers in heart failure: putting guidelines into practice. Eur J Heart Fail 2005; 7:710-721.

20. Heywood JT, Fonarow GC, Yancy CW, Albert NM, Curtis AB, Gheorghiade M, Inge PJ, McBride ML, Mehra MR, O'Connor CM, Reynolds D, Walsh MN. Comparison of medical therapy dosing in outpatients cared for in cardiology practices with heart failure and reduced ejection fraction with and without device therapy: report from improve HF. Circ Heart Fail 2010;3:596-605.
21. Aranda JM Jr, Woo GW, Conti JB, Schofield RS, Conti CR, Hill JA. Use of cardiac resynchronization therapy to optimize beta-blocker therapy in patients with heart failure and prolonged QRS duration. Am J Cardiol 2005;95:889-891.

22. Dickstein K, Vardas PE, Auricchio A, Daubert JC, Linde C, McMurrayJ, Ponikowski P, Priori SG, Sutton R, van Veldhuisen DJ. Committee for Practice Guidelines of the European Society of C, Guidelines ESCCfP. 2010 focused update of esc guidelines on device therapy in heart failure: an update of the 2008 ESC guidelines for the diagnosis and treatment of acute and chronic heart failure and the 2007 ESC guidelines for cardiac and resynchronization therapy. Developed with the special contribution of the heart failure association and the European heart rhythm association. Eur J Heart Fail 2010;12:1143-1153.

23. Steffel J, Hurlimann D. Current practice of cardiac resynchronization therapy (CRT) in the real world: insights from the European CRT survey. Eur Heart/ 2009;30:2433-2435.

24. Packer M, Poole-Wilson PA, Armstrong PW, Cleland JG, Horowitz JD, Massie BM, Ryden L, Thygesen K, Uretsky BF. Comparative effects of low and high doses of the angiotensin-converting enzyme inhibitor, lisinopril, on morbidity and mortality in chronic heart failure. Atlas study group. Circulation 1999;100:2312-2318.

25. Konstam MA, Neaton JD, Dickstein K, Drexler H, Komajda M, Martinez FA, Riegger GA, Malbecq W, Smith RD, Guptha S, Poole-Wilson PA, Investigators H. Effects of high-dose versus low-dose losartan on clinical outcomes in patients with heart failure (HEAAL study): a randomised, double-blind trial. Lancet 2009; 374:1840-1848

26. Mantziari L, Guha K, Khalique Z, McDonagh T, Sharma R. Relation of dosing of the renin-angiotensin system inhibitors after cardiac resynchronization therapy to longterm prognosis. Am J Cardiol 2012;109:1619-1625.

27. Hitz L, Kuhne MS, Sticherling C, Osswald S, Schaer BA. Adjustments of heart failure medication after implantation of a cardiac resynchronization therapy defibrillator. Minerva Med 2012;103:361-367.

28. JuurlinkDN, Mamdani MM, Lee DS, Kopp A, Austin PC, Laupacis A, Redelmeier DA Rates of hyperkalemia after publication of the randomized aldactone evaluation study. N Engl I Med 2004;351:543-551.

29. Voigt A, Shalaby A, Adelstein E, Saba S. Beta-blocker utilization and outcomes in patients receiving cardiac resynchronization therapy. Clin Cardiol 2010;33:E1-E5.

30. Grosu A, Senni M, lacovoni A, Gori M, Cantu F, Bisetti S, De Santo T, De Luca A, Gavazzi A. Cardiac resynchronization in combination with beta blocker treatment in advanced chronic heart failure (CARIBE-HF): the results of the CARIBE-HF study. Acta Cardiol 2011;66:573-580

31. The effect of digoxin on mortality and morbidity in patients with heart failure. The digitalis investigation group. N Engl J Med 1997;336:525-533.

32. Gheorghiade M, Fonarow GC, van Veldhuisen DJ, Cleland JG, Butler J, Epstein AE, Patel K, Aban IB, Aronow WS, Anker SD, Ahmed A. Lack of evidence of increased mortality among patients with atrial fibrillation taking digoxin: findings from post hoc propensity-matched analysis of the affirm trial. Eur Heart J 2013;34:1489-1497.

33. WhitbeckMG, Charnigo RJ, KhairyP, Ziada K, Bailey AL, Zegarra MM, ShahJ, Morales G, Macaulay T, Sorrell VL, Campbell CL, Gurley J, Anaya P, Nasr H, Bai R, Di Biase L, Booth DC, Jondeau G, Natale A, Roy D, Smyth S, Moliterno DJ, Elayi CS. Increased mortality among patients taking digoxin-analysis from the affirm study. Eur Heart J 2013:34:1481-1488.

34. Rathore SS, Curtis JP, Wang Y, Bristow MR, Krumholz HM. Association of serum digoxin concentration and outcomes in patients with heart failure. JAMA 2003; 289:871-878.

35. Ahmed A, Husain A, Love TE, Gambassi G, Dell'Italia LJ, Francis GS, Gheorghiade M, Allman RM, Meleth S, Bourge RC. Heart failure, chronic diuretic use, and increase in mortality and hospitalization: an observational study using propensity score methods. Eur Heart J 2006;27:1431-1439.

36. Eshaghian S, Horwich TB, Fonarow GC. Relation of loop diuretic dose to mortality in advanced heart failure. Am J Cardiol 2006;97:1759-1764.

37. Mielniczuk LM, Tsang SW, Desai AS, Nohria A, Lewis EF, Fang JC, Baughman KL, Stevenson LW, Givertz MM. The association between high-dose diuretics and clinical stability in ambulatory chronic heart failure patients.J Card Fail 2008;14:388-393.

38. Fung JW, Chan JY, Kum LC, Chan HC, Yip GW, Zhang Q, Yu CM. Suboptimal medical therapy in patients with systolic heart failure is associated with less improvement by cardiac resynchronization therapy. Int / Cardiol 2007;115:214-219.

39. Bristow MR, Saxon LA, Boehmer J, Krueger S, Kass DA, De Marco T, Carson P, DiCarlo L, DeMets D, White BG, DeVries DW, Feldman AM, Comparison of Medical Therapy P. Defibrillation in heart failure I. Cardiac-resynchronization therapy with or without an implantable defibrillator in advanced chronic heart failure. N Engl J Med 2004;350:2140-2150

40. Remme WJ, Riegger G, Hildebrandt P, Komajda M, Jaarsma W, Bobbio $M$, Soler-Soler J, Scherhag A, Lutiger B, Ryden L. The benefits of early combination treatment of carvedilol and an ACE-inhibitor in mild heart failure and left ventricular systolic dysfunction. The carvedilol and ACE-inhibitor remodelling mild heart failure evaluation trial (CARMEN). Cardiovasc DrugTher 2004;18:57-66. 
41. Khattar RS, Senior R, Soman P, van der Does R, Lahiri A. Regression of left ventricular remodeling in chronic heart failure: comparative and combined effects of captopril and carvedilol. Am Heart J 2001;142:704-713.

42. Pieske BM. Reverse remodeling in heart failure-fact or fiction? Eur Heart J Suppl 2004;6(suppl D):D66-D78.

43. Gasparini M, Regoli F, Ceriotti C, Galimberti P, Bragato R, De Vita S, Pini D, Andreuzzi B, Mangiavacchi M, Klersy C. Remission of left ventricular systolic dysfunction and of heart failure symptoms after cardiac resynchronization therapy: temporal pattern and clinical predictors. Am Heart J 2008;155 507-514.

44. Kutyifa V, Kloppe A, Zareba W, Solomon SD, McNitt S, Polonsky S, Barsheshet A, Merkely B, Lemke B, Nagy VK, Moss AJ, Goldenberg I. The influence of left ventricular ejection fraction on the effectiveness of cardiac resynchronization therapy: MADIT-CRT (multicenter automatic defibrillator implantation trial with cardiac resynchronization therapy). J Am Coll Cardiol 2013;61:936-944 